\title{
Editorial
}

\section{Advancing Screening and Prevention to the Next Level!}

\author{
Hans-Dieter Allescher ${ }^{a} \quad$ Holger Eduard Vogelsang ${ }^{b}$ \\ ${ }^{a}$ Center for Esophageal and Gastrointestinal Motility Disorders, Center for Internal Medicine, \\ Gastroenterology, Hepatology and Metabolism, Klinikum Garmisch-Partenkirchen, Garmisch-Partenkirchen, \\ Germany; ${ }^{b}$ Department of General, Visceral, Thoracic and Endocrine Surgery, Klinikum Garmisch-Partenkirchen, \\ Teaching Hospital, Ludwig Maximilian University Munich, Garmisch-Partenkirchen, Germany
}

How do we want to avoid or reduce gastrointestinal cancer deaths? Sure, by improving therapeutic options, that means targeted and individualized drugs as well as surgical techniques. But how about lifestyle management, identifying high-risk persons and families, early tumor detection, and treatment of preneoplastic changes by endoscopic surveillance, molecular tests, genetic risk assessment, and even prophylactic surgery? There are plenty of opportunities already but these are often insufficiently used. There are new evolving strategies we have to keep up with!

The implementation of general colorectal cancer screening programs in several countries has shown an anticipated decrease of the incidence of these malignancies with a subsequent reduction of mortality. Thus, these programs decrease the disease burden and subsequently the costs for the diagnosis and treatment of this tumor entity. Screening is probably the best way to fight against cancer and the strategies to optimize cancer screening must be improved.

There is good evidence that screening colonoscopy is still not optimal, and several activities have been established to further increase the efficacy of colonoscopy as a screening tool. While the role of colonoscopy for cancer screening is well established, other potential premalignant lesions such as Barrett esophagus and gastric lesions are not screened in a systemic approach in the western world. Therefore, these topics are dealt with in more detail regarding screening for Barrett mucosa and its premalignant changes as well as a possible role of a screening upper gastrointestinal endoscopy.

However, screening of the whole population is difficult and costly, and the question is raised whether primary prevention using nutrition and lifestyle management should not be advocated as a major factor for the prevention of gastrointestinal cancer.

Another way to better target screening and surveillance programs is the identification of risk groups and a tailored approach for each individual based on personal risk factors, family history, and genetic risk. This is dealt with in an up-to-date review on the current knowledge of genetic screening and personalized prevention in colorectal screening.

Certain risk situations are linked to highly penetrant germline mutations or a premalignant phenotype justifying prophylactic surgery with subtotal or total removal of the endangered organ. The current status of prophylactic surgery in gastric and colorectal cancer disposition is given.

We hope that the current issue gives the interested reader a good overview on the current status of screening and prevention in visceral medicine.

\section{KARGER}

(C) 2019 S. Karger AG, Basel
Prof. Dr. Hans-Dieter Allescher

Center for Internal Medicine, Gastroenterology, Hepatology and Metabolism Klinikum Garmisch-Partenkirchen

Auenstrasse 6, DE-82467 Garmisch-Partenkirchen (Germany)

E-Mail Hans-Dieter.Allescher@ klinikum-gap.de 